\title{
The building blocks and origins of life
}

Author:
Dirk U. Bellstedt ${ }^{1}$ (
Affiliation:
'Department of Biochemistry,
Faculty of Science,
Stellenbosch University,
Stellenbosch, South Africa
Corresponding author:
Dirk U. Bellstedt,
dub@sun.ac.za
Dates:
Received: 24 Apr. 2020
Accepted: 03 July 2020
Published: 22 Sept. 2020
How to cite this article:
Bellstedt, D.U., 2020,
'The building blocks and
origins of life', HTS Teologiese
Studies/Theological Studies
76(1), a6054. https://doi.
org/10.4102/hts.v76i1.6054
smart phone or
mobile device
to read online.
Copyright:
C2020. The Authors.
Licensee: AOSIS. This work
is licensed under the
Creative Commons
Attribution License.

The building blocks and origins of life have fascinated scientists since the earliest of times. What is required for life to work in terms of building blocks? An outline of the building blocks that have to be present in living systems to allow the processes that are required for life is given. These building blocks have to be organised in a specific way to allow living processes to be functional, which are summarised in what is referred to as the seven pillars of life. In essence, these are the fundamental characteristics of all living systems. Evidences of when and how living systems developed on the Earth shortly after the Earth established itself as a planet are discussed. This comes from the growing body of geological evidence of the age of rocks and rock formations in different places on the Earth. This review is concluded with the latest evidence of where on Earth living systems may have started. A large amount of uncertainty exists about these processes, but more and more consilient evidence is giving us important pointers as to the origins of life on the planet Earth.

Contribution: As part of this special collection, the building blocks or origins of life give insights into the chemical principles and constituents of living organisms and how their interactions allow life to function on earth.

Keywords: Origins of life; Earth's origins; Biomolecule; Bio-elements; Seven pillars of life; Early life; Hydrothermal vents; Last universal common ancestor.

\section{Introduction}

For the layperson, the chemical functioning of her or his body may not be of particular interest; the main interest would be to eat a healthy diet and lead a healthy lifestyle to allow a full, functional and hopefully long life. However, when a person is not well, be it from an upset tummy to a life-threatening disease, the question arises as to what makes my body work, and what keeps me healthy. This then leads to having to understand the chemistry of what is going on inside my body, and how this all works in a coordinated manner to generate life or living organisms. This can get tremendously complex, and we certainly do not understand how all of this functions, but biochemistry has certainly come very far in our understanding of how living organisms function.

In a general study in biology of the chemistry of living organisms, students would start off by studying the simplest of building blocks from which living organisms are built up (e.g. in Appling et al. 2016) and proceed to study ever-higher organisational levels of the components that built up living organisms (e.g. Mathews et al. 2012). This would start with a study of the simple atoms that we are built up of to the very complex molecules that perform specific functions in our bodies, to molecules that allow us to interact with each other and how we react to the environment. These studies are so complex, and we know so much about them by now, that numerous fields of specialisation have developed in biology, and a single student would never study the whole macrocosm of living organisms on Earth or beyond for that matter, if we were to accept that life could also exist elsewhere in the universe.

In this review, I wish to outline why living organisms are built up of certain building blocks; there are definite chemical reasons for why certain elements are found there and others not. However, my review does not address and actually cannot address what it is that causes what I refer to as the 'spark of life'. I could take all of the atoms that are found in a specific living organism and mix them in a container, but that would never lead to that collection of atoms being a living organism, without them being organised into the required structure with, most importantly, the spark of life. This seldom comes across as strongly as it does when a person dies, be it a young or an old person; from the one moment to the next, that person is living and shortly afterwards is dead, and the spark of life has left his or her body. Where that spark of life comes from is what has puzzled many scholars for centuries, and much has been

Note: Special Collection entitled Challenging Building Blocks: The coherence of cosmological evolution, life, consciousness, morality and building the 21 st century, sub-edited by Chris Jones (SUN) and Juri van den Heever (SUN). 
written about the topic. In my review I do not intend to discuss this; my objective here is to explain why the atoms that we find in living organisms are there and how they contribute to making a living organism functional. The spark of life is something that comes from elsewhere and is something that has puzzled humanity since its existence.

So why do we find certain atoms in living organisms and others not? One may use the term: 'Why have they been chosen'? but that may be taken to infer that someone, or some higher being, has chosen them. Again, this may lead to considerable debate, but in my review, I only wish to investigate and point out the specific chemical reasons as to why certain atoms are found in living organisms. What can be observed is that the building blocks of living organisms fulfil very specific roles. They serve as components of bigger structures or as part of the whole organism and have such an important role to play that without them, the total living organism cannot survive. So, if I pose the question in my review, 'why have they been chosen?', my question is aimed at the chemical reason only. Depending on one's religious conviction, you may want to give credit to someone or a higher being for this, and it is not my intention to doubt this in my review; my review is aimed at explaining the role that atoms play in biological systems only.

\section{The building blocks of living systems}

Any modern biology and biochemistry textbook (e.g. Appling et al. 2016; Mathews et al. 2012; Raven et al. 2020) would start off with a brief outline of the building blocks of life, specifically which types of atoms occur in biological systems, and summarise why they are used as building blocks. All of the different types of atoms that occur have been studied by chemists for over 100 years and are referred to elements and have been organised according to their properties in what is called the periodic table. A study of the elements that are shown in the periodic table reveals that not all are building blocks of biological systems, but rather that those that form a part of living organisms are present because of their specific properties. Three main groups of atoms or elements are found in living systems:

1. The elements that can form what are referred to as covalent bonds

2. The elements referred to as monoatomic ions

3. The so-called trace elements.

1. The elements that can form covalent bonds are carbon $(\mathrm{C})$, nitrogen $(\mathrm{N})$, oxygen $(\mathrm{O})$, hydrogen $(\mathrm{H})$, phosphorous (P) and sulphur (S). Atoms of these elements make up the bulk of building blocks of living organisms, and a high percentage of the mass of any living organism would be made up of these elements. In comparison with the elements of which the Earth's crust is made up, they only form a small part of the Earth's crust. Chemically, these different atoms are used to build up bigger structures which we refer to as molecules. For the purposes of this discussion, we must also clarify what covalent bonds are.
Without going into the chemistry in depth, both of the atoms that are bonded together by such bonds contribute to the bonds themselves, and these bonds are quite strong. In relation to other types of bonds, however, they are weak enough to be broken. By this nature, these building blocks are typical building blocks in that they can be linked to each other to form bigger structures, but the bonds between them are also weak enough that they can be broken down. This ongoing linking and breaking of these bonds is vital to allow the processes in a living organism to proceed. These bonds also allow the storage of energy in them, and this energy can then be used to drive processes that maintain a living organism. Each one of these building blocks has its own set of particular properties that decide how they can be linked together, and this in turn decides which functions they can perform. As any two of these different atoms can be linked together with covalent bonds and in turn can be linked to another atom, the molecules that can be built up can be quite large and can also perform the many functions that are required to maintain life. Typically, biochemists classify these bigger molecules into different groups, which may be familiar to the reader, such as proteins, carbohydrates, fats and nucleic acids. In turn, each of these so-called macromolecules plays a vital role in living organisms.

2. The elements referred to as mono-atomic ions that are found in biological systems are sodium $\left(\mathrm{Na}^{+}\right)$, potassium $\left(\mathrm{K}^{+}\right)$, chloride $\left(\mathrm{Cl}^{-}\right)$, magnesium $\left(\mathrm{Mg}^{2+}\right)$ and calcium $\left(\mathrm{Ca}^{2+}\right)$ ions. I have written these in their correct chemical format to show that they have charges on their surfaces. These ions, which occur in relatively high concentrations in living organisms, perform specific functions but are not involved in forming large structures as the previous group of elements are. Because of their charges, they can be attracted to molecules with opposite charges. In an analogy with humans, they can very often be referred to as accompanying persons, and they make the molecules that they accompany 'happier' in that they neutralise or level out charges, thereby making them more neutral and less reactive or attractive for other molecules. Interestingly, the fact that they are found in living organisms may be interpreted to infer that living organisms developed in the oceans, as these monoatomic elements are all found in seawater.

3. The so-called trace elements, as the name infers, only occur in trace amounts in living organisms. The most important of these are manganese $(\mathrm{Mn})$, iron $(\mathrm{Fe})$, cobalt $(\mathrm{Co})$, copper $(\mathrm{Cu})$ and zinc $(\mathrm{Zn})$, but the following also occur: boron (B), aluminium (Al), silicon (Si), molybdenum (Mo), vanadium $(\mathrm{V})$, chromium $(\mathrm{Cr})$, wolfram $(\mathrm{W})$, nickel $(\mathrm{Ni})$, gallium $(\mathrm{Ga})$, arsenic (As), selenium (Se), bromide $(\mathrm{Br})$, iodine $(\mathrm{I})$ and fluorine $(\mathrm{F})$.

You may ask, why bother, if they occur only in trace amounts. The answer to this question lies in their ability, mostly in combination with large molecules formed by the six elements mentioned in Point 1, to allow those atoms to perform very specific functions, such as a transfer of electrons 
in a oxidation reduction reaction, or to bind specific molecules, often to allow transport from one place in an organism to another. A typical example is the transfer of electrons during an oxidation reduction reaction of iron $\left(\mathrm{Fe}^{2+}\right.$ to $\left.\mathrm{Fe}^{3+}\right)$ during the process of photosynthesis in plants. This reaction allows the capture of energy from sunlight in plants so that this energy can be used for the production of carbohydrates. As plants essentially supply all energy to animals, the role of iron in photosynthesis is critical for the survival of life on Earth; the actual amount of iron needed for photosynthesis is tiny, as it is reused time and time again. A similar situation is the role that iron plays in the large molecule, haemoglobin, made up of the elements in Point 1, which transports oxygen in the blood of humans and other mammals. Again, iron is present in tiny amounts and is reused, but without it oxygen transport in the blood of mammals would be impossible.

Another example is molybdenum (Mo), the properties of which are critical for a very important enzyme, nitrate reductase, to perform its function. An enzyme is a biological catalyst. Catalysts allow reactions to be speeded up, which is essential for living organisms to function. The reactions joining the atoms outlined in Point 1 need to be formed and broken time and time again during living process and need to take place rapidly or else a living organism cannot function. So in the case of plants, the nitrate reductase enzyme containing molybdenum speeds up the conversion of nitrate to ammonia. Why is this critical for the plant? Nitrate occurs in the Earth's crust as a result of lightning strikes in the atmosphere, where the electrical energy converts nitrogen gas (containing the element $\mathrm{N}$ ) to nitrate. Nitrate itself, however, cannot be incorporated in the plant before it is converted to ammonia, which is performed by nitrate reductase. Ammonia is then used in the plant as a building block of proteins. All animals need to obtain their proteins (which are molecules composed of the atoms outlined in Point 1) from plants, as they do not have an enzyme similar to nitrate reductase. So, although molybdenum is only needed by plants to perform as a part of nitrate reductase, to be able to make proteins, this enzyme indirectly also supplies all animals with the nitrogen that they need to build up proteins.

I could continue giving more examples such as these, but the important point I wish to convey is that although only tiny amounts of trace elements are required in living systems, they fulfil essential roles, which they can perform with these tiny amounts as they can be recycled repeatedly.

\section{How are the building blocks of life organised to give rise to living cells?}

The collection of building blocks mentioned above needs to be organised in a very specific way to allow them to form a cohesive system, to work together and to function as a living system. It may sound simple to distinguish between a living and a dead system, but with the growing biochemical knowledge of what was required to form the functional units of life, it did require very careful formulation of thought and analysis to define this. The fundamental principles of an organisational system enabling life were published in a key article by Koshland in 2002 and are now referred to as the seven pillars of life (Koshland 2002). The concepts of this organisational system were developed to potentially cover artificial life and extraterrestrial life as well. The seven pillars of life are programme, improvisation, compartmentalisation, energy, regeneration, adaptability and seclusion, which will be explained hereafter:

- Programme: Life cannot exist or proceed without the molecules in the living system being organised in such a way that they execute a programme or maintain a programme. This includes a description of the components of the system (described above) and how these components interact as the life of the system proceeds, or as life proceeds. In life as we know it on the Earth, this programme proceeds through information stored in molecules (nucleic acids such as deoxyribonucleic acid [DNA] and ribonucleic acid [RNA]), which are used to synthesise specific proteins, which then execute the processes that ensure that a system may maintain itself over time. In all animals and plants, the molecule in which information is stored is DNA, which also applies to most bacteria; there are organisms such as some viruses, which store their information in RNA. In all living organisms on Earth, proteins execute the processes to allow life to proceed.

- Improvisation: In the long-term maintenance of life, the processes of improvisation require that a living system adjust itself to the possible changes in the environment. In this context, environment is meant in the broadest definition. The change in the environment can be changes in the local environment in which a living organism occurs, such as increases in temperature, reduction of water availability and food availability, or much bigger changes in the Earth's temperature as a whole or the world's atmosphere. If the animal cannot change its lifestyle or if the molecules in the animal cannot adapt themselves to the changing environment, the animal cannot survive in the long run and will die and become extinct. In essence, this is evolutionary change according to the principles of selection and survival of the fittest as proposed by Darwin in his theory of evolution. It should be noted that biologists view improvisation as a fundamental principle for life to exist on this planet.

Having made this statement, however, it must be added that biologists do not prescribe how these processes take place, and, in other words, that they take place shaped by the forces of the environment alone, or whether a higher being was responsible for shaping these processes. That is left entirely to the conviction of the individual. The expression 'do you believe in evolution?' is therefore a misnomer here; you may, according to your religious conviction, believe that this process was conducted by a higher 
being or not, and biologists have no reason to doubt this. There needs to be no conflict about the concept of evolution, as evolutionary biologists have no grounds on which to reject that a higher being may be involved in these processes. Each of us can do this according to our own religious conviction; the fact of the matter is that improvisation is a fundamental process without which living systems cannot survive in the long run. The Earth's surface has not been constant over the ages; the composition of the atmosphere and the crust has changed remarkably over time.

- Compartmentalisation: All living systems have to be limited in their extent to a definite volume, which is surrounded by a substance to keep its contents within that volume and not allow its contents to leak out in an uncontrolled fashion. Only within the confines of such a controlled space can a living system function. Without the confines of a controlled space, a living system would be unable to coordinate the processes required for life to continue. That does not mean that substances cannot be exchanged with the environment that occurs around the compartmentalised space; on the contrary, it is essential for living systems to obtain substances such as foodstuffs from outside and to eject waste substances from the inside. In order for life to continue, however, the molecules mentioned above must be accumulated to sufficient concentrations in this space to allow them to perform the functions required for living processes to continue. On the other hand, compartmentalisation means that toxins cannot enter, which could harm the processes required for life to continue. The smallest unit of compartmentalisation of living processes is the cell. However, many living organisms are made of many cells, many of which then have cells that are differentiated to perform different functions. In all animals and plants, cells with similar functions occur together in tissues or organs, but all cells are fundamentally surrounded by what are called cell membranes to ensure compartmentalisation.

- Energy: It is essential for living systems to obtain energy from somewhere outside of the system. Sunlight supplies energy to plants, and foodstuffs eaten by animals supply energy. Microbes take in foodstuff molecules from the environment around them. This must be done to fuel the living system and to allow it to convert the molecules referred to in Point 1 . We all know that we cannot survive without food intake; so all other living systems must also take in food to survive. A living system is therefore not a balanced system in equilibrium with its environment; it cannot work or live without this ongoing intake from outside. Directly or indirectly, all living organisms on Earth are dependent on the sun for their energy.

- Regeneration: During the release of energy from foodstuffs, the machinery of the living system suffers from wear and tear. It therefore requires maintenance and repair. As an example, to explain this, Koshland calculates that the heart beats, say, 60 times per minute, 3600 times per hour, 1314000 times per year and over a lifetime approximately 91 million times. This cannot happen without ongoing repair or regeneration. Not only do molecules within living systems have to be repaired, but often the whole compartmentalised cells themselves have to be replaced by new cells that need to be regenerated on an ongoing basis.

- Adaptability: In the short term, adaptability may involve the action of cells moving away from a source of heat or the action of flight of an animal moving away from a predator. In animals (and humans), there are complex mechanisms whereby the eyes see a threat, this gets converted to a signal to the brain, the brain decides that the animal needs to move away from the threat, nervous impulses travel via the nervous system to the muscles and, in a process controlled by the brain, the animal then moves or runs away from the threat. These processes often only take seconds, and such systems and their components are incredibly complex, yet they are essential to ensure the day-to-day life of the animal. In bacteria, adaptability mechanisms are simpler and on a smaller scale, but most bacteria also possess mechanisms whereby they can move away from possible threats and towards more favourable areas. Adaptability is therefore essential for the survival of all living systems.

- Seclusion: Within a living system, molecules need to be converted from one type to another for energy production or the production of building blocks and for other applications. This takes place via what are called metabolic pathways, which biochemists have researched extensively and now understand very well. However, these pathways may not be mixed up; otherwise, the end products that are required eventually cannot be produced. An analogy would be that different cables conduct electricity independently, but if they come into contact with each other they would be short-circuited. To ensure that the molecules are channelled through separate metabolic pathways, the enzymes (the biological catalysts mentioned earlier) that perform the conversions in such pathways are highly specific and 'do not get mixed up' and convert the wrong molecules. In some living systems, this takes place by further compartmentalisation of the cell in organelles such as the nucleus, the mitochondria and the chloroplasts, beside many other minor compartmentalised organelles. Organelles are also surrounded by membranes to bring about this compartmentalisation.

Although this may sound very convincing, it must be remembered that the seven pillars of life that Koshland formulated were described in an article in the prestigious journal Science would and should not categorically accepted as being a fact by the general public and the scientists of this world. This is a hypothesis or a set of hypotheses. Before science accepts a hypothesis as being correct, it requires experimental proof. In order for us to assess whether Koshland's seven pillars may be valid, they must be evaluated in the light of scientific evidence that may support or reject them. It is actually very difficult to test some of these hypotheses because one cannot simply 
assemble a system containing the components of living organisms and give the correct spark of life, as I have explained before, and expect that system to 'live' all of a sudden. Life is a very special thing, and to test whether it arose or started more than once would almost be impossible to assess.

\section{When and how did living systems as we know them develop on Earth?}

Having therefore discussed the components of living systems and the fundamental principles of living systems, the next and very obvious questions that must be asked are when and how did they develop? In view of the complexity of the components and fundamental principles of living systems, these questions require very complex answers. Scientists seeking to answer these questions would, of course, like to find tangible evidence of this, by finding some evidence in the Earth's crust indicating how these early living systems may have looked or functioned. Direct evidence of how living systems evolved cannot be found easily, but scientists have tried to infer this by laboratory experiments or geological evidence and more recently from the information that is stored in the DNA of present-day living organisms by using bioinformatics analyses. The amount of information about this is by now extensive and often very difficult for the non-scientist not only to find, but even to try to understand.

If geological evidence is taken into account, then the Earth is estimated to be about 4.5 billion years old (Manhesa et al. 1980; Zahnle et al. 2007). Up until about 20 years ago, it was thought that after the formation of the Earth, it must have undergone a very unstable period in terms of the Earth's surface itself and its atmosphere. During this time, the surface of the Earth would have had a very high temperature $\left(\sim 2000^{\circ} \mathrm{C}\right)$, and massive electrical storms were thought to have taken place. This prompted the development of an earlier dogma that life on Earth must have arisen from this overheated world, in which substances could have reacted and formed molecules which could have been utilised by primitive living systems when the Earth cooled down thereafter. In 1953, Stanley Miller (1953) attempted to simulate what may have happened under those conditions. He manufactured a glass apparatus in which he could add substances and in which he could expose these substances to an electrical discharge and therefore extreme heat and then cool them off in repeated cycles of hot and cold. In 1959, Miller and Urey published an article describing which products would form under these conditions. If hydrogen gas $\left(\mathrm{H}_{2}\right)$, methane $\left(\mathrm{CH}_{4}\right)$, ammonia $\left(\mathrm{NH}_{3}\right)$ and water $\left(\mathrm{H}_{2} \mathrm{O}\right)$ are added into this apparatus and the contents are then exposed to the electrical discharge for a week, it would lead to the formation of a number of carbon-containing compounds, as they are found in living organisms, importantly a number of amino acids and organic acids, mainly formic acid. Following on from these early experiments, numerous experiments were conducted with the objective of trying to establish whether other molecules that are found in living organisms, especially the so-called nitrogenous bases found in DNA and RNA, could be synthesised under these conditions. It has now been confirmed that under conditions of both electric discharge and laser-driven plasma impact, the synthesis of nitrogenous bases can take place (Ferus et al. 2017). It can therefore be concluded that many of the molecules required by living systems can be formed under conditions of extreme temperatures and irradiation; in other words, the synthesis of the building blocks of living systems is possible under the conditions that existed when the Earth was formed. Furthermore, oily substances such as those found in cell membranes are also synthesised as a result of these reactions. One other important aspect is that the atmosphere surrounding the primitive Earth was very oxygen poor, meaning that oxidation could not take place as we know it in the atmosphere of the modern world. The large-scale release of oxygen into the Earth's atmosphere only took place when photosynthesis started taking place in bacteria, which was later transferred to plants. This changed the Earth's atmosphere around 2 billion years ago and meant that oxygen as the acceptor and donor of electrons in biochemical reactions could take place. This was very important for the generation of energy from foodstuffs. By implication, this also means that in primitive living systems, oxygen was not present, and energy was most probably delivered by what are known as thio-esters, which are sulphur-containing biological molecules.

As I have indicated above, a dogma that the surface of the Earth had gone through an extended period of extreme heat and with an atmosphere with ongoing electrical discharges persisted until about 20 years ago. Evidence showing that this not to have been the case is now emerging (Arndt \& Nisbet 2012), and instead it is thought that the surface of the Earth cooled down much faster after its initial formation. Thus, it is thought that by 4.3 billion years ago the Earth had cooled sufficiently so that the seawater temperature was as cool as $26^{\circ} \mathrm{C}-35^{\circ} \mathrm{C}$ (Blake, Chang \& Lepland 2010, as referred to by Arndt \& Nisbet 2012). This is a topic which is subject to ongoing debate, but this certainly means that much cooler temperatures prevailed on the Earth's surface much earlier than previously thought.

In terms of direct geological evidence, the earliest evidence for life on Earth comes from hydrothermal vents, which have become encased in rock formations found in Quebec, Canada (Dodd et al. 2017), dated at 3.77 billion years ago. These authors found microscopic iron-containing (haematite) tubes and filaments which also contained carbon, which they interpreted as evidence of microorganisms living at hydrothermal vents. Further evidence for life on Earth comes from rock deposits called stromatolites found in northern 
Australia that are approximately 3.5 billion years old (Baumgartner 2019). These are rocks that contain layers of iron pyrites (consisting of iron and sulphur) and nitrogencontaining organic material organised in filaments or strands. What does this evidence present in simple terms? Firstly, the tubes and filaments found in these rock formations are interpreted as evidence of structures that would surround or encapsulate this living matter, in other words, evidence of compartmentalisation and seclusion in terms of the seven pillars of life. The iron pyrite deposits that are evidence of iron and sulphur are evidence of an earlier type of metabolism of microorganisms, in which they used sulphur instead of oxygen in their energy-delivering metabolism. Lastly, the organic material containing nitrogen, carbon and hydrogen indicates that these elements, which are essential components of living systems, were found in these rocks.

Only very recently has an approach been developed to try to place together the biochemical processes that were performed by early living systems from the information that is stored in the DNA of present-day living organisms by using bioinformatics analyses. This relates to the first of the pillars of life that was referred to earlier, that is a programme, without a programme and maintenance of a programme, life cannot exist. Thanks to the development of techniques that can sequence the whole DNA content of organisms with a high degree of accuracy, greater speed and lower cost, the information contained in this DNA, in other words, the code for the 'programme', can now be analysed. Using high speed and high data capacity computers, one can now analyse the information content much more efficiently than before using bioinformatic analysis. If a comparison is now made of the information in all organisms, ranging from primitive bacteria to more modern bacteria, to plants and all animals, then information that is common to all can be identified. That which is different is precisely the information that encodes for the differences between the organisms, but if those sequences that are common to all living organisms are sifted out, then this information can be used to trace the information in their common ancestor. This is therefore almost a sort of a 'back to basics' approach. This approach has now been used to reconstruct the biochemical processes that most likely occurred in the ancestor of all living systems and is called the last universal common ancestor (LUCA) approach (Weiss et al. 2016, 2018). This has now brought to light that the biochemical processes that produced the energy required for living systems to survive were dependent on iron and sulphur and not dependent on oxygen, as is the case in modern living systems, where oxygen replaces sulphur. This therefore further supports the claim that during the early development of living systems, oxygen was not freely available wherever these living systems developed. It is startling to see what this approach reveals regarding the most primitive living systems. Again, the seven pillars of life, the fundamental principles of an organisational system enabling life, can be identified in this reconstructed system.

\section{Where did living systems start?}

In this review, I have indicated which building blocks are required for living systems to be functional, how the building blocks of life are organised to give rise to living cells and when and how living systems as we know them developed on Earth. Given all of this evidence, the question still remains: where did living systems most likely start? Scientists have therefore used all of these lines of evidence to postulate a hypothesis for where life most likely developed on the planet Earth. All of the following would need to be at such a place: the building blocks required, the mechanisms for supplying energy for the system to function, the molecules required to encapsulate the living system and molecules that would allow for information to be stored in them. After very careful consideration of all of these factors, the conclusion to which scientists have come is that the most likely place in which life evolved is at the hydrothermal vents that are still found deep on the ocean floor today (Arndt \& Nisbet 2012; Dodd et al. 2017). The earliest geological evidence for a specific place where such hydrothermal vents existed is in the Isua Belt, in southwestern Greenland (Grassineau et al. 2006; Rosing 1999).

\section{Conclusion}

In my review of the building blocks of life, I have tried to steer away from complex chemistry and chemical terminology to try to explain this to persons not qualified in the fields of biochemistry and phylogenetics. Living systems are built up of building blocks in a highly organised manner to construct living systems. Scientists try to find evidence for how living systems were developed, by looking for consilience between different lines of evidence. From this, a common picture is emerging, but there are still major gaps in our understanding of when, where and how living systems developed. Many questions will however remain and cannot be answered, because no one was there at the time when the remarkable processes initiating life were started.

\section{Acknowledgements}

I wish to thank my colleagues and students for stimulating discussions on this topic over many years.

\section{Competing interests}

The author declares that he has no financial or personal relationships that may have inappropriately influenced him in writing this research article.

\section{Author's contributions}

D.U.B. is the sole author of this research article.

\section{Ethical considerations}

This article followed all ethical standards for research without direct contact with human or animal subjects. 


\section{Funding information}

This research received no specific grant from any funding agency in the public, commercial or not-for-profit sectors.

\section{Data availability statement}

Data sharing is not applicable to this article as no new data were created or analysed in this study.

\section{Disclaimer}

The views and opinions expressed in this article are those of the author and do not necessarily reflect the official policy or position of any affiliated agency of the author.

\section{References}

Appling, D.R., Spencer, J., Anthony-Cahill, S.J. \& Mathews, C.K., 2016, Biochemistry concepts and connections, Pearson Publishers, London.

Arndt, N. \& Nisbet, E., 2012, 'Processes on the young Earth and the habitats of early life', Annual Review of Earth and Planetary Sciences 40(1), 521-549. https://doi. org/10.1146/annurev-earth-042711-105316

Baumgartner, R.J., Van Kranendonk, M.J., Wacey, D., Fiorentini M.L., Saunders, M., Caruso, S. et al., 2019, 'Nano-porous pyrite and organic matter in 3.5-billion-yearold stromatolites record primordial life', Geology 47(11), 1039-1043, https://doi. org/10.1130/G46365.1

Blake, R.E., Chang, S.J., Lepland, A., 2010, 'Phosphate oxygen isotope evidence for a temperate and biologically active Archean ocean', Nature 464(7291), 1029-1032, https://doi.org/10.1038/nature08952

Dodd, M., Papineau, D., Grenne, T., Slack, J.F., Rittner, M., Franco Pirajno, F. et al., 2017, 'Evidence for early life in Earth's oldest hydrothermal vent precipitates', Nature 543(1), 60-64. https://doi-org.ez.sun.ac.za/10.1038/nature21377
Ferus, M., Pietrucci, F., Saitta, A.M., Knížek, A., Kubelík, P., Ivanek, O. et al., 2017, 'Formation of nucleobases in a Miller-Urey reducing atmosphere' Proceedings of the National Academy of Sciences 114(17), 4306-4311. https://doi.org/10.1073/ pnas.1700010114

Grassineau, N.V., Abell, P., Appel, P.W.U., Lowry, D. \& Nisbet, E.G., 2006, 'Early life signatures in sulphur and carbon isotopes from Isua, Barberton, Wabigoon (Steep Rock) and Belingwe greenstone belts ( 3.8 to $2.7 \mathrm{Ga}$ )', in S.E. Kesler \& (Steep Rock) and Belingwe greenstone belts ( 3.8 to $2.7 \mathrm{Ga}$ )', in S.E. Kesler \&
$\mathrm{H}$. Ohmoto (eds.), Evolution of early Earth's atmosphere, hydrosphere and $\mathrm{H}$. Ohmoto (eds.), Evolution of early Earth's atmosphere, hydrosphere and
biosphere - Constraints from ore deposits, pp. 33-52, Geological Society of America Special Publications, Boulder, CO

Koshland, D.E. Jr., 2002, 'The seven pillars of life', Science 295(5563), 2215-2216. https://doi.org/10.1126/science.1068489

Manhesa, G., Allègre, C.J., Dupréa, B. \& Hamelin, B., 1980, 'Lead isotope study of basic-ultrabasic layered complexes: Speculations about the age of the earth and primitive mantle characteristics', Earth and Planetary Science Letters 47(3), 370-382. https://doi.org/10.1016/0012-821X(80)90024-2

Mathews, C.K., Van Holde, K.E., Appling, D.R., Spencer, J. \& Anthony-Cahill, S.J., 2012 Biochemistry, 4th edn., Pearson Academic Publishing, New York, NY.

Miller, S.L., 1953, 'A production of amino acids under possible primitive earth conditions', Science 117(3046), 528-529. https://doi.org/10.1126/science.117. 3046.528

Miller, S.L. \& Urey, H.C., 1959, 'Organic compound synthesis on the primitive earth' Science 130(3370), 245-251. https://doi.org/10.1126/science.130.3370.245

Raven, P.H., Johnson, G.B., Mason, K.E., Losos, J. \& Duncan, T., 2020, Biology, 12th edn., McGraw-Hill, Boston, MA.

Rosing, M., 1999, '13C-depleted carbon in $>3700-$ Ma sea-floor sedimentary rocks from West Greenland', Science 283(5402), 674-676. https://doi.org/10.1126/ science.283.5402.674

Weiss, M.C., Preiner, M., Xavier, J.C., Zimorski, V. \& Martin, W.F., 2018, 'The last universal common ancestor between ancient earth chemistry and the onset of genetics', PLOS Genetics 14(1), e1007518. https://doi.org/10.1371/journal. pgen.1007518

Weiss, M.C., Sousa, F.L., Mrnjavac, N., Neukirchen, S., Roettger, M., Nelson-Sathi, S. et al., 2016, 'The physiology and habitat of the last universal common ancestor', Nature Microbiology 1(9), 16116. https://doi.org/10.1038/nmicrobiol. 2016.116

Zahnle, K., Arndt, N., Cockell, C., Halliday, A., Nisbet, E. \& Selsis, F., 2007, 'Emergence of a habitable planet', Space Science Review 129(1), 35-78. 